\title{
Peer Review of the Trusted Software Methodology
}

by G.H. Chisholm, J.D. Gannon," R.A. Kemmerer," and J. McHugh*

Decision and Information Sciences Division,

Argonne National Laboratory, 9700 South Cass Avenue, Argonne, Illinois 60439

February 1994

Work sponsored by the Office of the Secretary of Defense,

Ballistic Missile Defanse Organization, and by the National Security Agency

"Gannon is affiliated with the University of Maryland; Kemmerer with the University of California, Santa Barbara; and McHugh with Portland State University.

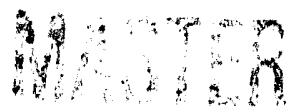


This report is printed on recycled paper. 


\section{CONTENTS}

NOTATION $\ldots \ldots \ldots \ldots \ldots \ldots \ldots \ldots \ldots \ldots \ldots \ldots \ldots \ldots \ldots \ldots \ldots \ldots \ldots \ldots, v$

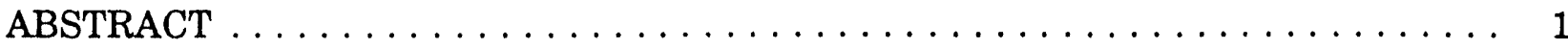

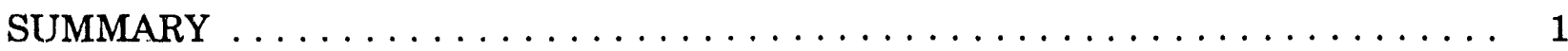

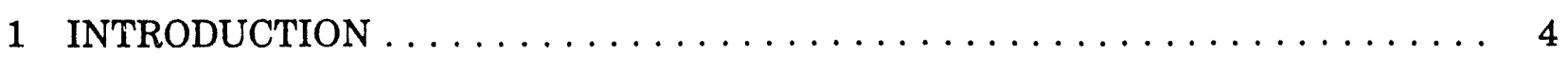

1.1 Approach for Conducting the TSM Review $\ldots \ldots \ldots \ldots \ldots \ldots \ldots \ldots$

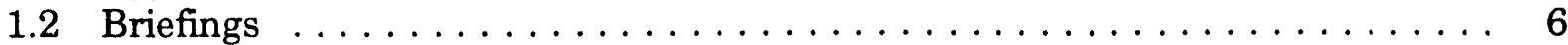

1.2.1 BMDS and Information Architecture $\ldots \ldots \ldots \ldots \ldots \ldots \ldots 6$

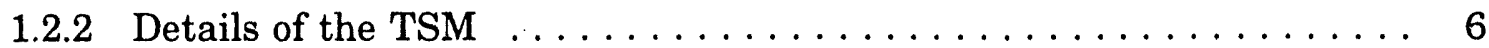

1.2.3 Experiences with the Application of the TSM $\ldots \ldots \ldots \ldots \ldots \ldots 6$

2 THE TRUSTED SOFTWARE METHODOLOGY $\ldots \ldots \ldots \ldots \ldots \ldots \ldots \ldots$

2.1 Original Task $\ldots \ldots \ldots \ldots \ldots \ldots \ldots \ldots \ldots \ldots \ldots \ldots \ldots \ldots \ldots \ldots \ldots \ldots$

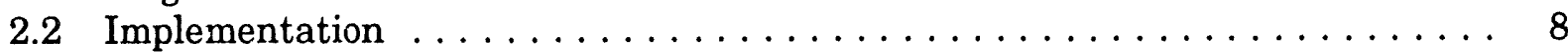

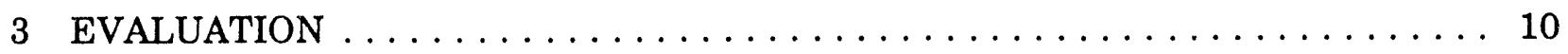

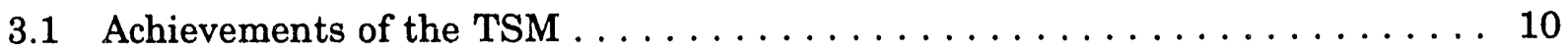

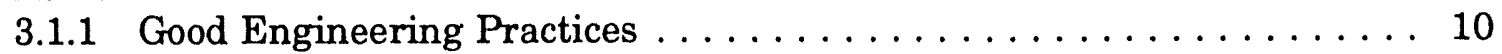

3.1.2 Visibility into the Software Engineering Process $\ldots \ldots \ldots \ldots \ldots 10$

3.1.3 Enhanced Evaluation Capability $\ldots \ldots \ldots \ldots \ldots \ldots \ldots \ldots \ldots 11$

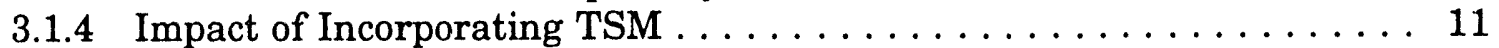

3.1.5 Tailoring of the Software Development Process . . . . . . . . . 11

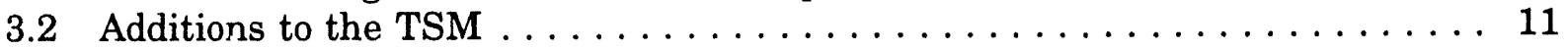

3.2.1 Mapping from Threats to Threat Principles .............. 12

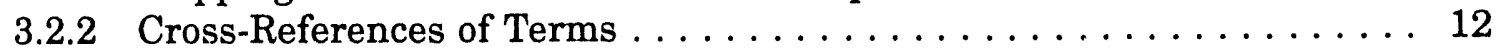

3.2.3 Empirical Evidence $\ldots \ldots \ldots \ldots \ldots \ldots \ldots \ldots \ldots \ldots \ldots \ldots \ldots$

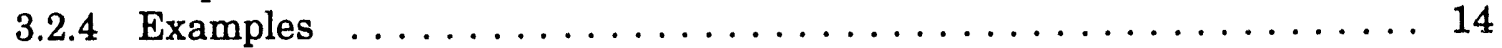

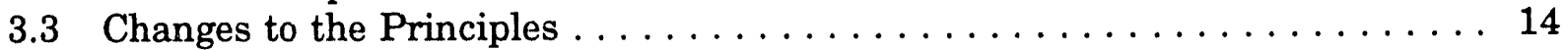

3.3.1 Small Differences between Compliance Requirements . . . . . . . . 15

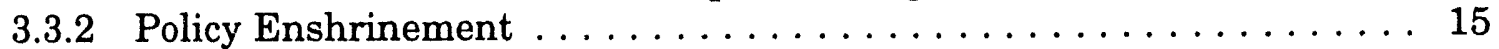

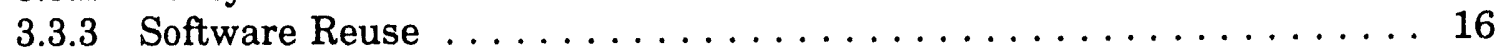

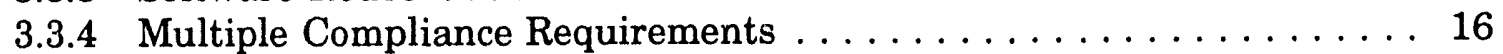

3.3.5 Correlation of Threats and Principles $\ldots \ldots \ldots \ldots \ldots \ldots \ldots 17$

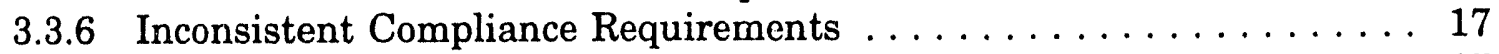

3.3.7 Arbitrary Separation of Review Process Principles ............ 17

3.3.8 Checklist Usage . . . . . . . . . . . . . . . . . . . . . 18

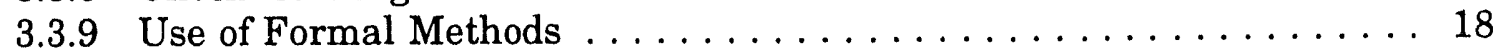

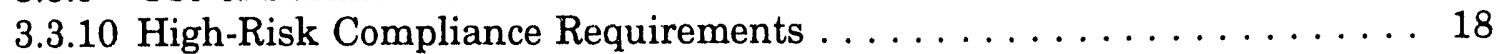

3.3.11 Application of Trust Principles to the TSM $\ldots \ldots \ldots \ldots \ldots \ldots 18$ 


\section{CONTENTS (Cont.)}

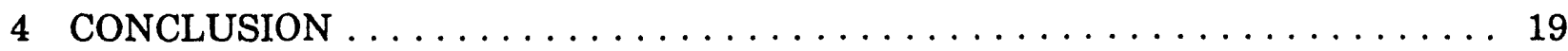

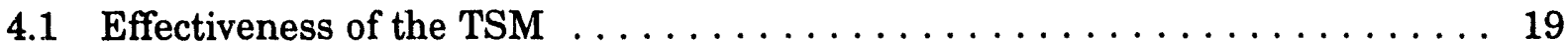

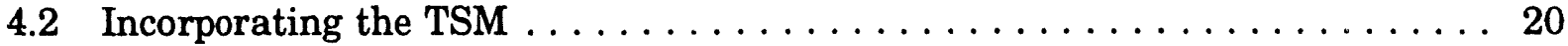

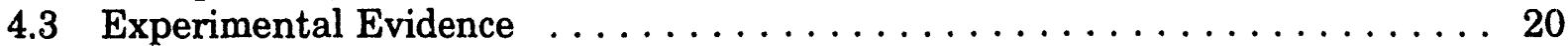

4.4 Additional Empirical Evidence $\ldots \ldots \ldots \ldots \ldots \ldots \ldots \ldots \ldots \ldots \ldots \ldots \ldots \ldots \ldots \ldots$

4.5 TSM and Software Fingineering Processes $\ldots \ldots \ldots \ldots \ldots \ldots \ldots \ldots \ldots \ldots$

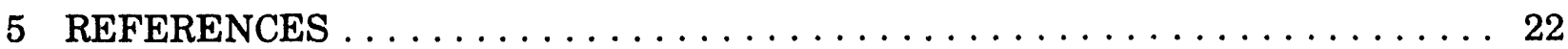

\section{TABLES}

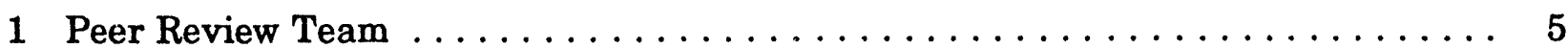

2 TSM Trust Levels and Compliance Requirements $\ldots \ldots \ldots \ldots \ldots \ldots \ldots$ 


\section{NOTATION}

$\mathrm{BM} / \mathrm{C}^{3} \quad$ Battle Management, Command, Control, and Communication BMDO Ballistic Missile Defense Organization

BMDS Ballistic Missile Defense System

CASE computer-aided software engineering

CMM Capability Maturity Model

DAC discretionary access control

DoD U.S. Department of Defense

IDA Institute for Defense Analysis

MLS multilevel security

SDI

SDP

SDS

SEE

SEIC

Strategic Defense Initiative

software development plan

Strategic Defense System

software engineering environment

TSM

system engineering and integration contractor

Trusted Software Methodology 


\title{
PEER REVIEW OF THE TRUSTED \\ SOFTWARE METHODOLOGY
}

by

\author{
G.H. Chisholm, J.D. Gannon, R.A. Kemmerer, and J. McHugh
}

\begin{abstract}
The review and analysis of the Trusted Software Methodology (TSM) by a panel of experts in various areas of computer science, computer security, and engineering are reported. The approach to the conduct of the review is described, and a brief introduction to the TSM is provided. The findings from the review fall into three categories: achievements, desirable additions, and changes. In addition, several recommendations are made with respect to application of the TSM within the purview of the Ballistic Missile Defense Organization.
\end{abstract}

\section{SUMMARY}

The Trusted Software Methodology (TSM) was developed to reduce the risks associated with both the inadvertent introduction of flaws into software and malicious attempts to subvert software during the development process. It is a compendium of 25 trust principles, each of which is supported by a number of compliance requirements. The compliance requirements support the evaluation of software development processes according to five classes of trustworthiness, ranging from T1 (good commercial practice) to T5 (state of the art). The TSM fulfills two primary objectives: it defines a software development process that will help to ensure a trustworthy software product, and it supports the systematic gathering and presentation of evidence to document that trustworthiness. In the case in which developers of a system are not responsible for operating that system, this chain of evidence is as important as the product.

A panel of experts in various areas of computer science, computer security, and engineering reviewed the TSM. The panel's findings fall into three categories:

- Achievements of the TSM,

- Additional information needed to evaluate the TSM properly, and

- Changes that should be made to improve the trust principles and their corresponding compliance requirements. 
These findings support the following recommendations:

- The TSM should be used to develop trusted software. The trust principles and compliance requirements of the TSM represent some of the best software development practices available.

- A "checklist" mentality should be avoided. The trust principles and compliance requirements of the TSM define substantive activities, but they will not be effective unless they are applied and evaluated by individuals who understand the threats to trusted development. Software managers and developers must remain cognizant of their responsibility to ensure proper application of the TSM. Reducing the compliance requirements to a checklist stresses form over function, and form alone is not sufficient.

- The TSM should be applied to future work on the information architecture for the Ballistic Missile Defense System. Architectural decisions being made now could complicate the development of a trustworthy system. Application of the TSM could nullify a trend toward undue complexity.

- Both the government and its contractors should make a total, across-theboard commitment to the TSM because they must work together to achieve a trustworthy system. To be able to evaluate the resulting system, government program managers must understand the process by which the system was developed. To convince these program managers that the system is trustworthy, the contractor must supply evidence. A commitment to the TSM provides a framework for both tasks.

The TSM reflects some of the best software development practices in use today, many of which are currently being applied in both the government and the commercial sectors. However, these practices may be applied in an ad hoc fashion. The TSM provides a mechanism for structuring their application to obviate specific threats.

The panel's suggestions for additions and changes to the TSM are in the spirit of making a good thing better. They are as follows:

- More precision in defining and using terms and addition of an indexing mechanism to ensure consistent use of terms.

- More systematic collection of evidence to support the claimed effectiveness of the TSM, and

- Correction of problems with the compliance requirements. 
Relatively minor changes in the TSM will remedy most of these problems. The panel recognizes, however, that it is difficult to gather empirical evidence regarding the effectiveness of any software engineering methodology. Such a task is beyond the scope of the TSM effort. 


\section{INTRODUCTION}

The Strategic Defense Initiative Organization Panel on the security and integrity of Strategic Defense Initiative (SDI) assets (Davis 1988) reported a number of recommendations that addressed computer security concerns:

The security and integrity of SDI assets in its entirety is critical to the success of both the development of the SDI and the operation of the SDS [Strategic Defense System]. Immediate attention must be given by the director and senior management to:

1. The unique features of the SDI/SDS security problem,

2. A security life-cycle approach for handling SDI/SDS security,

3. A process for secure software development, and

4. An information systems security architecture.

In response to the findings of this report, the National Security Agency was tasked with providing oversight for the development of the Trusted Software Methodology (TSM).

The TSM was developed to reduce the risks associated with both the inadvertent introduction of flaws into software and malicious attempts to subvert software during the development process. It is a compendium of 25 trust principles, each of which is supported by a number of compliance requirements. These compliance requirements support evaluation of software development processes according to five classes of trustworthiness, ranging from T1 (good commercial practice) to T5 (state of the art). The TSM aims to produce trustworthy software by improving software engineering processes. This restrictive view is an artifact of the orientation established at the start of the development of the TSM.

Since the original release of the TSM, its developers have incorporated suggestions from an informal review conducted by a community of prospective users of the TSM, primarily within the purview of the Ballistic Missile Defense Organization (BMDO). These reviewers have concentrated on issues associated with applying the TSM to specific parts of the Ballistic Missile Defense System (BMDS). However, such reviews may concentrate on implementation-related issues and fail to address global issues that systematically affect the TSM. In recognition of this possibility, a formal peer review of the TSM was convened to answer questions at a global level. The panel considered the following questions:

- Does the TSM provide adequate safeguards and counterm " prs to mitigate perceived threats and vulnerabilities?

- Can the TSM effectively be merged into a prospective user's design process? 
- What experimental evidence supports the claim that the TSM will produce a better product?

- Is there an agenda for supporting the claims for the TSM?

- How does the TSM differ from standard software engineering processes?

\subsection{APPROACH FOR CONDUCTING THE TSM REVIEW}

On October 14-15, 1993, a peer review of the TSM was conducted in Vero Beach, Florida, by a panel of experts in various areas of computer science, computer security, and engineering. The panel consisted of representatives from academia, industry, and national laboratories (Table 1). The panel received briefings and conducted interviews in an attempt to perform an unbiased review of the TSM. The findings from this review fall into three categories: achievements, desirable additions, and changes. The panel also provided recommendations regarding continued use of the TSM to improve BMDO products.

The developers of the TSM selected the material to be presented, and the moderator of the peer review panel requested briefings on the BMDS and information architectures.

TABLE 1 Peer Review Team

\begin{tabular}{|c|c|c|}
\hline Name/Title & Organization & Field of Expertise \\
\hline $\begin{array}{l}\text { G.H. Chisholm, } \\
\text { Computer engineer }\end{array}$ & $\begin{array}{l}\text { Argonne National } \\
\text { Laboratory }\end{array}$ & $\begin{array}{l}\text { Computer engineering, dependable } \\
\text { system design }\end{array}$ \\
\hline $\begin{array}{l}\text { J.D. Gannon, } \\
\text { Professor }\end{array}$ & University of Maryland & $\begin{array}{l}\text { Software requirements, analysis, } \\
\text { and testing }\end{array}$ \\
\hline $\begin{array}{l}\text { R. Gibson, } \\
\text { Vice president }\end{array}$ & Motorola & Software engin€ering \\
\hline $\begin{array}{l}\text { R.A. Kemmerer, } \\
\text { Professor and chairperson }\end{array}$ & $\begin{array}{l}\text { University of California, } \\
\text { Santa Barbara }\end{array}$ & $\begin{array}{l}\text { Formal methods, computer } \\
\text { security, and software engineering }\end{array}$ \\
\hline $\begin{array}{l}\text { J. McDermott, } \\
\text { Senior researcher }\end{array}$ & $\begin{array}{l}\text { Naval Research } \\
\text { Laboratory }\end{array}$ & Security and security evaluation \\
\hline $\begin{array}{l}\text { J. McHugh, } \\
\text { Tektronix Professor }\end{array}$ & Portland State University & $\begin{array}{l}\text { Security, software engineering, } \\
\text { and formal methods }\end{array}$ \\
\hline $\begin{array}{l}\text { A. Marmor-Squires, } \\
\text { Senior technologist }\end{array}$ & TRW Systems Division & $\begin{array}{l}\text { Software engineering, process, and } \\
\text { computer security }\end{array}$ \\
\hline $\begin{array}{l}\text { H.D. Mills, } \\
\text { President }\end{array}$ & $\begin{array}{l}\text { Software Engineering } \\
\text { Technology, Inc. }\end{array}$ & Software engineering \\
\hline
\end{tabular}


The peer review panel met in private sessions to encourage free and unbiased discussions of the TSM. In addition, no representatives of the funding agents were present during the review.

Four members of the panel made up the "core" team. In addition to participating in the review, the core team also attended an abbreviated TSM training session and was charged with writing this report.

Modifications are currently being made to the TSM, and the documentation and training associated with the TSM remain incomplete with respect to these modifications. However, the relevant documentation (i.e., that concerning the trust principles) is essentially complete. For purposes of this report, the term "TSM" refers to the collection of documents that define the TSM (DoD 1992a-c) and to the Trusted Software Development Course (1993).

\subsection{BRIEFINGS}

The briefings that supported the review fell into three general areas: BMDS architecture, details of the TSM (e.g., trust principles, training, and guidelines), and experiences in the application of the TSM.

\subsubsection{BMDS and Information Architecture}

The TSM is predicated on the mitigation of threats to the BMDS. To quickly familiarize the review panel with this system, the system engineering and integration contractor (SEIC) presented a briefing on relevant architectural approaches. Paul Dayton, a representative of the SEIC, provided background information on the Battle Management, Command, Control, and Communication $\left(\mathrm{BM} / \mathrm{C}^{3}\right)$ information architecture and the BMDS architecture.

\subsubsection{Details of the TSM}

John Watson, also representing the SEIC, provided briefings that gave insight into the TSM, including motivations for its development, detailed descriptions of the trust principles, improvements made since its inception, training procedures, and guidelines for its use.

\subsubsection{Experiences with the Application of the TSM}

Another set of briefings concerned experiences associated either with direct application of the TSM or with investigations into the appropriateness of applying the TSM. Kathy Hiles, Teledyne Brown Engineering, provided a briefing from a trust evaluator's perspective. She described experiences relative to the BMDO's software engineering support 
environment project. This effort targets development just below level T4 (i.e., T4 from the previous TSM documentation without the application of formal specifications).

Dave Brozyna, National Security Agency, related experiences in applying the TSM to the Windjammer project (level T3).

Jim Gosler, Sandia National Laboratories, provided a briefing from the perspective of an analyst. He discussed the threats and vulnerabilities of systems and the effect that the TSM would have in both decreasing the probability that penetrations would go undetected and simplifying the analyst's task.

John Boone, Institute for Defense Analysis (IDA), provided a briefing on a survey of software engineering processes at 15 diverse companies, including five U.S. Department of Defense (DoD) contractors. The intent of this survey was to determine the current state of the practices at these companies with respect to the requirements of the TSM. 


\section{THE TRUSTED SOFTWARE METHODOLOGY}

The purpose of the TSM is to reduce the potential for both malicious and inadvertent subversion of BMDS software during its entire life cycle. The specification, design, coding, testing, integration, and maintenance principles of the TSM establish inherent protective attributes or built-in safeguards that make the software design, development, and maintenance process less vulnerable to threats of subversion. The TSM provides the BMDS software manager, developer, and evaluator with guidance on ways to integrate safeguards and countermeasures into the software life-cycle process to address specific threats and vulnerabilities. The DoD Trusted Computer System Evaluation Criteria refer to this type of protection as "Lifecycle Assurance - the steps taken by an organization to ensure that the system is designed, developed, and maintained using formalized and rigorous controls and standards" (DoD 1985).

\subsection{ORIGINAL TASK}

Sophisticated software development methods must be used to construct, field, and maintain secure systems. The goals of the TSM are to define explicit steps to ensure and quantify that software provides the required functionality with a high degree of reliability, to define measures to detect and prevent the introduction of malicious functionality, to define capabilities that minimize the vulnerabilities within the software engineering process, and to provide safeguards for all life-cycle phases, including maintenance.

\subsection{IMPLEMENTATION}

The TSM is made up of a set of 25 trust principles and corresponding sets of compliance requirements. The trust principles represent policies, procedures, and controls from the best existing software and security engineering practices for reducing vulnerabilities to specific threats. The principles are grouped into five classes that provide increasing levels of trust, and compliance requirements are associated with each trust principle (Table 2). By using a process that complies with these principles, software developers should be able to provide a degree of assurance that their software is trustworthy because such a process reduces flaws and vulnerabilities in the software development and maintenance process. 
TABLE 2 TSM Trust Levels and Compliance Requirements

\begin{tabular}{|c|c|c|}
\hline $\begin{array}{l}\text { Trust } \\
\text { Level }\end{array}$ & Compliance Requirements & Process Attributes Used \\
\hline $\mathrm{T} 1$ & $\begin{array}{l}\text { Approximately corresponds to } \\
\text { the current development } \\
\text { processes of commercial } \\
\text { developers }\end{array}$ & $\begin{array}{l}\text { Fundamental software engineering practices } \\
\text { (i.e., planning, risk management, configuration } \\
\text { management, administration, documentation, } \\
\text { informal reviews) }\end{array}$ \\
\hline $\mathrm{T} 2$ & $\begin{array}{l}\text { Approximately corresponds to } \\
\text { the development processes used } \\
\text { by most DoD developers who } \\
\text { work with classified materials }\end{array}$ & $\begin{array}{l}\text { Fundamental DoD/Institute of Electrical and } \\
\text { Electronics Engineers-type documentation, } \\
\text { standards, reviews, corrective actions, and } \\
\text { configuration management; automated support of } \\
\text { development activities; provisions for process } \\
\text { improvement; fundamental closed-environment } \\
\text { security policies and controls }\end{array}$ \\
\hline T3 & $\begin{array}{l}\text { Approximately corresponds to } \\
\text { the best practices of DoD } \\
\text { developers who work with } \\
\text { classified materials }\end{array}$ & $\begin{array}{l}\mathrm{C} 2 / \text { system-high controls to maintain product and } \\
\text { software engineering environment (SEE) } \\
\text { integrity; specific attention to vulnerabilities that } \\
\text { can be exploited by malicious activities; } \\
\text { fundamental controls on transfer of software } \\
\text { items outside the SEE; increased rigor in product } \\
\text { evaluation activities (i.e., inspections); formal } \\
\text { testing process (i.e., documentation, standards, } \\
\text { independence) }\end{array}$ \\
\hline $\mathrm{T} 4$ & $\begin{array}{l}\text { Approximately corresponds to } \\
\text { the practices of developers of } \\
\text { highly sensitive and critical } \\
\text { applications }\end{array}$ & $\begin{array}{l}\text { B1/multilevel security (MLS) controls to maintain } \\
\text { product and SEE integrity; active search for } \\
\text { unauthorized changes to the product under } \\
\text { development and the SEE; reliability engineering } \\
\text { as an integral part of the software life cycle; } \\
\text { shared knowledge requirements for all software } \\
\text { items and multiperson control on changes to } \\
\text { items under configuration control }\end{array}$ \\
\hline T5 & $\begin{array}{l}\text { Approximately corresponds to } \\
\text { state-of-the-art practices, which } \\
\text { include experimental } \\
\text { development methods }\end{array}$ & $\begin{array}{l}\text { Maximal use of MLS capabilities for access } \\
\text { control and accountability; independence of } \\
\text { administrative activities that can be abused to } \\
\text { hide malicious activity; formal specification and } \\
\text { verification }\end{array}$ \\
\hline
\end{tabular}




\section{EVALUATION}

\subsection{ACHIEVEMENTS OF THE TSM}

\subsubsection{Good Engineering Practices}

The trust principles embody good software and security engineering practices. They represent a compilation and synthesis of requirements for high-quality software development processes. The underlying hypothesis of this effort is that by using such a process, developers will produce software that is more likely to meet its requirements and is less vulnerable to malicious attack. While the use of a high-quality software development process is necessary for reaching this goal (at least for large-scale systems), it may not be sufficient because of the difficulty in applying good software engineering methods. As Parnas (1985) states: "The methods reduce, but do not eliminate, errors. They reduce, but do not eliminate, the need for testing."

For example, the National Research Council (1993) studied independent verification and validation of National Aeronautics and Space Administration space shuttle avionics software. The study found that although developers had used the Capability Maturity Model (CMM) "level-5" software development process (Humphrey 1988; Software Engineering. Institute 1991), which relies heavily on inspections to detec ${ }^{\dagger}$, problems, the software still contained an error. This error resulted from a loss of precision that occurred when a doubleprecision arithmetic value was assigned to a single-precision variable. Such operations are used in shuttle sortware to conserve computer memory.

Although this error had not been seen on prior shuttle flights, it had been observed during previous testing on different hardware. The CMM development process did not expose the error because a compensating error in a run-time library routine (a single-precision comparison rather than a double-precision comparison) hid the error. When the library error was corrected, however, no inspection for further errors was triggered. Inspections focus on verifying the consistency of two module descriptions (e.g., requirements and design or design and co-te), and the correctness of the execution platform (e.g., system libraries, software tools, and hardware) is generally taken for granted. The National Research Council (1993) study observed that "[t]he inspection process is outstanding, but even IBM admits that it needs continuous improvement." This example shows that even a high-level development process requires changes and improvements.

\subsubsection{Visibility into the Software Engineering Process}

By providing enhanced visibility into their development processes, TSM users will enable other developers to reuse their products with a better understanding of associated risks. Project managers who use the TSM are likely to become more familiar with software development processes and, as a result, more active in their oversight of contractors' efforts. 
In reviewing current large embedded systems, managers must rely almost exclusively on the contractor's advice regarding the severity of flaws and the appropriate verification and validation method to determine whether a flaw has been corrected. Without a thorough understanding of the developer's process, the manager's role becomes mostly actuarial; the manager certifies that particular processes were executed, but without understanding those processes and their relative strengths and weaknesses.

\subsubsection{Enhanced Evaluation Capability}

Systems developed with good software engineering processes, such as those advocated by the TSM, make security evaluation much easier. Although such processes will not reduce the need for security evaluations, they will improve their quality. Individuals with significant experience in security analysis confirm this finding.

\subsubsection{Impact of Incorporating TSM}

Adopting TSM requirements (at least those at level T3) will not impose insurmountable burdens on DoD contractors. A survey of contractors conducted by IDA showed that DoD contractors already comply with $65-83 \%$ of the level T3 requirements. This survey was based on the June 17, 1992, version of the TSM, which associated 33 trust principles with level T3. The version of the TSM provided to the peer review panel incorporated changes identified during the IDA survey. On the basis of these changes, the panel speculates that the actual degree of compliance with T3 requirements by DoD contractors may be higher than that indicated by the survey.

In addition, individuals with direct experience in adopting level T3 requirements into existing, mature development processes confirm the higher compliance figure. However, it was beyond the scope of this study to determine the potential cost impacts of achieving $100 \%$ compliance.

\subsubsection{Tailoring of the Software Development Process}

One of the strengths of the TSM (particularly with respect to DoD [1985]) is that by separating trust concerns into individual principles, the TSM permits the software development process to be tailored to achieve a particular level of trust (e.g., the developers interviewed characterized their efforts as "almost T4"). Separating trust concerns also permits developers to respond strongly to specific threats perceived to be more likely in the software's operating environment.

\subsection{ADDITIONS TO THE TSM}

Ideally, a thorough review of the TSM requires the following: a clear statement of goals of the TSM (i.e., the threats that the principles address) so that their appropriateness 
can be determined, a more precise use of terms so that claims made about the effectiveness of the method can be tested, and empirical evidence that substantiates those claims. While budget constraints may limit the conduct of a case study, changes in the description of the TSM have eased the review of the TSM and would also facilitate its future use.

\subsubsection{Mapping from Threats to Threat Principles}

It would be useful to have a map that shows the connection between each threat and its associated threat principle. Section 1, paragraph 4, of Volume 1 of the TSM document (DoD 1992a) states:

The methodology provides guidance to the GPALS [Global Protection Against Limited Strike] software manager, software developer, and software evaluator on how to integrate safeguards and countermeasures into the software life cycle process to address specific threats and vulnerabilities.

This sentence seems to imply that such a mapping exists. The peer review panel realizes that specific threats observed in the field may be sensitive but believes that an abstraction of the threats could be achieved.

Without a map from threats to threat principles, it cannot be confirmed that the principles address genuine threats. The panel feels that code analysis should identify potential errors rather than achieve an arbitrary value of a software metric that may or may not be correlated with software errors.

\subsubsection{Cross-References of Terms}

Although the TSM documents (DoD 1992a) contain a glossary, it is often difficult to ascertain the meaning of key terms. In addition, inconsistent use of terms in different parts of the documentation increases the difficulty in understanding terminology. An example is the use of the word "consistency":

- The glossary defines consistency as "the property of logical coherency between and internal to constituent components of the software products and agreement with specified standards."

- Compliance requirement (c2) of the code analysis principle (A21) uses consistency to describe "characteristics of code which indicate the use of uniform design and implementation techniques and notation (i.e., consistency)."

- Compliance requirement (b) of the computer-assisted software engineering (CASE) tools principle (A20) states: "The development methodology supported by the CASE tools shall be consistent with the software development methodology employed on the project (e.g., 
structured design or object oriented design)." Requirement (d) adds "tools should be used to provide automated assistance ... for checking the internal consistency and interfaces of the requirements and designs."

- Compliance requirement (f) of the formal inethods principle (A24) states: "Each formal specification shall be analyzed to ensure internal consistency of the specification."

The use of the word "consistency" in these cases varies from a simple syntax check of interfaces to a check for logical soundness of a formal specification. The danger of contextsensitive uses of a term is that a compliance criterion that appears to be easy to achieve may turn out to be costly and difficult to achieve. It would be useful to cross-reference key terms used in the TSM documents. A data dictionary for these terms would be even better.

Another problem related to terminology is that some "claims" are too strong. For instance, the leading paragraph of the formal review principle (A18) states:

Peer reviews are conducted to ensure the completeness, consistency, and correctness of the software requirements, design, source code, tests, and support documentation.

Although peer reviews will enhance software quality, they cannot be used to "ensure" qualities as elusive as completeness and consistency.

\subsubsection{Empirical Evidence}

The software engineering literature contains experimental evidence that modern software engineering practices (e.g., structured programming, chief programmer techniques, and reviews) generally improve software products. However, there is little empirical evidence that a collection of processes taken from the software engineering literature, such as the TSM, will improve the resulting software product. That is, there is little evidence that the use of the TSM will reduce the potential for both inadvertent and malicious subversion of the software product being developed.

Additional empirical evidence to bolster the claims made about the TSM would be useful. The only existing evidence is the Trusted Software Experiment, which was a reimplementation of a previously developed application. That study was compliant only through trust level T3. In addition, because of the limited time available, the TSM was tailored to fit the case study. In particular, the panel noted an overlap in the detailed design, code, and computer software configuration item testing.

Obtaining empirical evidence to evaluate the effect of the TSM on total life-cycle costs is a difficult task. The costs of using the TSM in the development of a software product were estimated by using cost model analysis tools (SEER/SEM, REVIC, and CHECKPOINT), and these costs were compared with software developrnent costs for the original product (a tailored, 2167-A development) without the use of the TSM. The comparison indicated that 
the use of the TSM resulted in higher development costs than those of the original project. Additional development costs incurred as a result of using the TSM may be offset only by savings realized during integration testing and the remainder of the life cycle.

A case study of the development of a "new" project, with strict adherence to the TSM, and of the maintenance activities on the system is the only way to confirm the claims made about the TSM. Particular care should be taken in the design of a case study. The parameters of cost models should be validated with the same personnel, SEE, and type of application over long periods. Inaccurate estimation of parameters is likely to lead to meaningless results. As stated earlier, the panel recognizes that an idealized case study may be costly or time prohibitive for systems currently under development.

The IDA surveyed 15 organizations to determine the state of their practices with regard to the TSM and to identify compliance problems. The organizations were divided into three groups representing different types of software development organizations: DoD contractors, Trusted Computer System Evaluation Criteria developers, and commercial organizations. The results showed that the five DoD contractors surveyed had a high degree of compliance with level T3 requirements (65-83\%). This degree of compliance indicates that level T3 development may not place an excessive additional burden on these developers. Among the commercial participants, both developers using well-defined processes and those using undefined processes produced quality software, which led the IDA to conclude that the TSM may not include all factors that affect software quality.

\subsubsection{Examples}

The TSM trust principles describe requirements for software development processes without giving examples of particular methods that satisfy the principles. Examples would be useful to DoD contractors (and reviewers), who could simply adopt the suggested methods. At present, however, DoD contractors must select their own software development methods and convince trust evaluators appointed by program managers that the methods comply with the trust principles. The trust evaluator's role is defined only by requirements. Although additional details would probably decrease the variation in performance among different evaluators, the peer review panel was pleased with the description of evaluation activities provided. The trust evaluator formulated a set of questions for evaluating the compliance requirements associated with relevant trust principles and obtained evidence to support the developer's responses.

\subsection{CHANGES TO THE PRINCIPLES}

This section discusses some recommended changes to the trust principles. The changes are stated in general terms, and each change is illustrated with examples based on specific principles. The examples are by no means exhaustive. In dealing with the problems, careful attention must be given to all the principles. This task would be facilitated by a cross-reference or index of the principles. The numbering system used to refer to trust 
principles and compliance requirements is taken from the trust principles draft of October 12 , 1993 (DoD 1993).

\subsubsection{Small Differences between Compliance Requirements}

In some descriptions of trust principles, the reasons for separating compliance requirements by trust level are unclear. The additional effort required to achieve compliance with a higher trust level seems to be either insignificant or an integral part of the activity required at a lower level. For example, the planning principle (A1) requires detailed planning for each software life-cycle activity at level $\mathrm{T} 1$ and adds criteria for determining when these activities are complete at level T2. It is difficult to imagine developing and documenting a plan for these activities without considering completion criteria. The panel suggests an analysis of the differences between levels to justify the additional efforts in terms of the following:

- A significant effort required to comply with the new requirement that would not be expended in complying with related requirements of a lower level;

- A specific threat that is not considered at a lower level; and

- A significant added assurance against a threat considered but not completely mitigated at a lower level.

\subsubsection{Policy Enshrinement}

Some criteria seem to "enshrine" a particular policy or technique to the exclusion of others. This problem arises in several instances that deal with the security policy and its enforcement mechanisms. The security policy principle (A3) calls for the identification of "subjects and objects" and states several of its compliance requirements in these terms. These terms are most commonly used in connection with Bell and LaPadula (1976) style security policies. Some security policy styles, such as information flow and noninterference policies, do not explicitly use these concepts. In addition, many entities that may appear as part of the SEE have both subjectlike and objectlike characteristics. This problem is further compounded in the access control principle (A9), which implies that the policy implemented for a level T3 system must implement a conventional discretionary access control (DAC) policy, although no requirement for DAC for this class appears under the security policy principle, and the T3 requirements for security policy are stated in much broader language than the corresponding language of the access control principle.

These discrepancies may result from modifications to the security policy principle that have not been adequately tracked with respect to their effects on other principles. As noted previously, the use of a cross-referencing or data dictionary mechanism in connection with the development of the TSM would help to obviate problems of this kind. 


\subsubsection{Software Reuse}

The previously developed software integrity principle (A4) does not seem to result in an adequate level of assurance at any class. To ensure that reused software is not a source of threats and vulnerabilities, it must not be used without a level of assurance comparable to that obtained from application of the TSM at the class of interest. The risk mitigation activities identified under the reuse principle do not provide substantive assurance; they only recognize a potential problem. The panel has identified two acceptable alternatives for reusing software:

- Require that software imported into a development effort targeted for a given trust class be developed under a trusted development process that has achieved the same or a higher class, or

- Develop a product evaluation process that can provide the same degree of assurance for products developed under other processes (or no process at all) as for products developed under the TSM.

The panel notes that the principle is to apply to SEE components as well as to software to be incorporated into products developed by using the SEE. The CASE tools principle (A19) places substantially stronger and more specific requirements on the reuse of CASE tools than does the previously developed software integrity principle. The panel recommends merging the CASE tool principle with the previously developed software integrity principle.

\subsubsection{Multiple Compliance Requirements}

Compliance requirements for specific items appear under multiple trust principles. Several examples of this problem have been noted. Some represent a situation in which specific requirements are levied for one instance of a general case but not for others. One such example is the specific compliance requirements applied to the importation of CASE tools under the CASE tool principle (A19). It is not clear why these requirements should apply to CASE tools and not to other tools that are part of the SEE or to software intended for reuse in the product being developed. In other cases, more requirements seem to be added to items that are partially specified under another principle. For example, the software development plan (SDP) is initially required under the planning principle (A1). Additional requirements are lescribed under the documentation principle (A15) and the reliability engineering principle (A23). The requirements of the documentation principle (A15) are particularly confusing because they refer to documents that either seem to be part of the SDP (e.g., software test plans) or are not explicitly required for compliance under other principles (e.g., software support and operational documentation).

This problem reflects a lack of orthogonality among the trust principles. While some overlap may be unavoidable, the inability to easily determine all of the compliance requirements associated with a given entity is troublesome as is the implicit requirement for 
the production of particular entities by levying requirements on them as a part of the compliance requirements for peripherally related trust principles.

\subsubsection{Correlation of Threats and Principles}

Principles do not always obviate threats. The lack of a mapping from threats to threat principles allows the development of compliance requirements that are not directly related to threats.

Undetected flaws pose a serious threat to trusted software. High values of software complexity metrics may not accurately predict the modules that contain flaws. The code analysis principle (A20) focuses on measuring complexity rather than detecting errors. Static analysis techniques can be used to detect errors such as uninitialized variables and improper sequences of operations. However, the compliance requirements for this item do not require the use of such techniques.

\subsubsection{Inconsistent Compliance Requirements}

Inconsistencies in trust levels exist among related compliance requirements for different trust principles. The compliance requirements for the testing approach principle (A21) and the test responsibility principle (A22) are all at level T3 or higher (i.e., beyond standard operating procedures for most commercial developers and DoD developers working with classified material). However, the documentation principle (A15) requires a software test plan at level T1. Thus, test plans for large classes of developers would include no compliance requirements for the test approaches that appear in the plans, which means that test plans could state that no testing will be performed.

\subsubsection{Arbitrary Separation of Review Process Principles}

The review process principles are arbitrarily separated. Two principles deal with reviews: the peer review principle (A17) and the formal review principle (A18). The main differences between activities associated with these principles are the persons who participate in the reviews (i.e., developer peers rather than representatives from program management, quality assurance, and configuration management) and the software products reviewed (i.e., intermediate work products rather than deliverable configuration items). Many of the compliance requirements for these two principles overlap (e.g., A17e and A18c, A17f and A18d, A17h and A18e, A17m and A18f, and A17p and A18i).

Common usage in software engineering distinguishes between "informal" and "formal" reviews on the basis of the distribution of the review products. Informal reviews circulate results within the review team and the developers of the reviewed items. Formal reviews circulate some results up the management hierarchy. This distinction may be useful in reorganizing these review principles. 


\subsubsection{Checklist Usage}

Reliance on checklists during reviews may discourage participants from exercising more critical analytic processes. Many review checklists contain analysis tasks that require relatively low-level cognitive skills (e.g., determining whether variables are properly initialized or that a function fails to return a value on one of its execution paths). Reviewers who find several anomalies on a checklist may believe that they have fulfilled their responsibilities and fail to determine whether the software implements its requirements.

\subsubsection{Use of Formal Methods}

Poor understanding of formal methods limits their potential to affect software development processes other than at the T5 level. Formal methods can be used to describe software systems and their properties. Limiting the application of formal methods to verification properties precludes their incremental introduction at other levels of the development processes for specification activities, static analysis, and testing. Some compliance requirements (e.g., A24b) enshrine certain popular notations as requirements.

\subsubsection{High-Risk Compliance Requirements}

Several compliance requirements are considerably beyond the state of the art. The documentation compliance requirement (A15b1) insists that documentation from each software life-cycle activity is "correct, consistent, and accurate with respect to products of previous life-cycle activities" (DoD 1992a). No techniques exist that ensure that documentation is correct or complete. The code analysis compliance requirement (A20c1) insists on the use of metrics to analyze the code to determine whether it fully implements required functions. No such code metric exists (or ever will exist).

\subsubsection{Application of Trust Principles to the TSM}

During the review, the panel noted little evidence that the compliance requirements embodied in the TSM had been applied to the development and maintenance of the TSM. This lack of evidence may well be an artifact of the review process. However, the requested development of a mapping from threats to trust principles and of a cross-reference of terms would ensure compliance with the planning principle (A1), as applied to the creation of a development plan for the TSM. 


\section{CONCLUSION}

\subsection{EFFECTIVENESS OF THE TSM}

Does the TSM provide adequate safeguards and countermeasures to mitigate perceived threats and vulnerabilities? The context for the TSM is the software engineering process; that is, the TSM applies to the transformation of system design requirements into a detailed design and implementation. The TSM establishes the trustworthiness of such a process and identifies five levels of trustworthiness, ranging from $\mathrm{T} 1$ (indicative of commercial developers) to $\mathrm{T} 5$ (state of the art), with increasingly stringent requirements applying to the higher levels. Within this context, the perceived threat to the BMDS is the introduction of flaws, whether inadvertent or malicious.

The TSM mitigates vulnerabilities to the malicious introduction of flaws by providing safeguards and countermeasures to the SEE and its administration and environs. These safeguards and countermeasures are invoked by a diverse set of trust principles. For example, the security policy principle (A3) invokes compliance requirement (q) (DoD 1993a): "The security policy shall define procedures used to ensure that all known security vulnerabilities in the SEE are identified. The vulnerabilities shall also be defined."

The TSM structure allows the compliance requirements to be tailored to a specific project. Thus, project members should invoke applicable compliance requirements to ensure adequate mitigation of the risks associated with identified threats and vulnerabilities.

Does the TSM provide sufficient information for a project to tailor a security policy? The answer is a qualified yes, if the TSM is modified in accordance with the suggestions of this report.

With respect to the inadvertent introduction of flaws during software design, the TSM delineates a compendium of trust principles with associated compliance requirements to mitigate the associated risk. Within the stated context of the TSM, the question is again one of sufficiency. However, the real value of the TSM is from a system perspective. That is, systems engineering firms have proven engineering processes in place. The difficulty arises when these firms make a transition to the use of digital technology. The TSM identifies software-specific engineering process requirements. Integration of the TSM into an existing engineering process should ease the transition.

The TSM elucidates some of the best software development practices available. In the context of the software engineering process, the TSM will identify safeguards and countermeasures against the introduction of design errors, subject to proper tailoring to the project. 


\subsection{INCORPORATING THE TSM}

Can the TSM effectively be merged into a prospective user's design process? Evidence presented during the review points to a generally positive answer.

- The TSM embodies some of the best software engineering practices.

- The TSM is configurable.

- A survey of the processes of five DoD contractors indicated a high level (65-83\%) of compliance with level T3 requirements.

- Systems are being designed to level T3 or higher.

However, the cost associated with incorporating TSM at level T3 may appear excessive if the target process has little structure

\subsection{EXPERIMENTAL EVIDENCE}

What experimental evidence supports the claim that the TSM will produce a better product? The software engineering literature contains experimental evidence that modern software engineering practices (e.g., structure programming, chief programmer technique, and reviews) generally result in improved software products. However, no empirical evidence shows that the collection of processes that compose the TSM will significantly improve the resulting software product. The panel notes that the single attempt to obtain experimental evidence directly related to the TSM is both incomplete and inconclusive. The attempt to manufacture results by extending what few data are available with predictions from models that have not been validated in this context does more harm than good.

The panel's belief that the TSM represents a desirable practice for development of security-critical and other trusted software is based on the aggregation of the experimental evidence available for its constituent components plus its collective experience as software developers and evaluators of software and software development processes. Another dimension of the term "better" must be taken into account in considering trusted software. It is not sufficient for the software simply to be trustworthy. The development process must produce a chain of evidence that allows an independent outside evaluator to conclude that the software is trustworthy. The TSM produces such a chain.

Is the TSM the best (or only) way to develop trusted software? The answer to this related question must be no, but the search for an optimal process may be futile and would require a commitment to observation, data collection, and experimentation over a long time. Even if such an effort were successfully undertaken, its results would not be available in the time frame required by the BMDO. Given that a variety of techniques could produce the desired results, the panel argues that adopting a uniform process throughout the BMDO would facilitate the evaluation of both process and product to an extent sufficient to warrant its imposition. 


\subsection{ADDITIONAL EMPIRICAL EVIDENCE}

Is there an agenda for supporting the claims for the TSM? The peer review panel agrees that empirical evidence to bolster the claims made about the TSM would be useful. However, the panel also recognizes that obtaining empirical evidence; to evaluate the effect of the TSM on total life-cycle costs is a difficult task. The panel recommends gathering empirical evidence about parts of the TSM that are "risky" (where it is not understood which technology to use) or "expensive" (where it is not understood how much effort it will take to use a technology). The panel notes that performing case studies of software methods is a difficult task that is best performed by persons who have successfully conducted empirical studies.

\subsection{TSM AND SOFTWARE ENGINEERING PROCESSES}

How does the TSM differ from standard software engineering processes? The TSM is differentiated from standard software engineering processes by trust. This answer implies that (1) the TSM may assess the trust potential of a given process and (2) the compliance requirements of the TSM may be integrated into an existing nontrusted process to enhance trust. 


\section{REFERENCES}

Bell, D.E., and L.J. LaPadula, 1976, Secure Computer System: Unified Exposition and Multics Interpretation, MTR-2997, Mitre Corporation, McLean, Va., March.

Davis, R.M., 1988, Interim Report of the SDIO Panel on the Security and Integrity of SDI Assets, The Pymatuning Group, Inc., Arlington, Va., for U.S. Department of Defense, Strategic Defense Initiative Organization, Washington, D.C., Feb. 19.

DoD, 1985, Trusted Computer System Evaluation Criteria, DoD 5200.28-STD, U.S. Department of Defense, Washington, D.C., Dec.

DoD, 1992a, Trusted Software Methodology, SDI-SD-91-000007, Volumes 1 and 2, U.S. Department of Defense, Strategic Defense Initiative Organization, Washington, D.C., June 17.

DoD, 1992b, GPALS Software Standards, SDI-P-SD-000005, U.S. Department of Defense, Strategic Defense Initiative Organization, Washington, D.C., Sept. 4.

DoD, 1992c, Guidelines for Allocating Software Trust Requirements, PIR 92416, U.S. Department of Defense, Strategic Defense Initiative Organization, Washington, D.C., Dec. 14.

DoD, 1993, Trusted Software Methodology, Appendix A: Software Trust Principles and Classes, U.S. Department of Defense, Strategic Defense Initiative Organization, Washington, D.C., Oct. 12.

Humphrey, W., 1988, "Characterizing the Software Process: A Maturity Framework," IEEE Software, July.

Naticnal Research Council, 1993, An Assessment of Space Shuttle Flight Software Development Processes, Committee for Review of Oversight Mechanisms for Space Shuttle Flight Software Processes, Aeronautics and Space Engineering Board, National Academy Press, Washington, D.C.

Parnas, D.L., 1985, "Software Aspects of Strategic Defense Systems," Communications of the ACM, 12:1326-1335, Dec.

Software Engineering Institute, 1991, Key Practices of the Capability Maturity Model, CMU/SEI-91-TR-25, Aug.

Trusted Software Development Course: Core Team Training Manual, 1993, Ballistic Missile Defense System Engineering and Integration Contractor (BMD SEIC), for U.S. Department of Defense, Washington, D.C., June. 


\section{DISTRIBUTION FOR ANL/DIS-1}

\section{Internal}

ANL Technical Publications Services

B. Waterman

N. Clodi (5)

G. Chisholm (112)

\section{External}

U.S. Department of Energy Office of Scientific and Technical Information (2) Manager, U.S. Department of Energy Chicago Field Office ANL-E Libraries (2)

ANL-W Library 


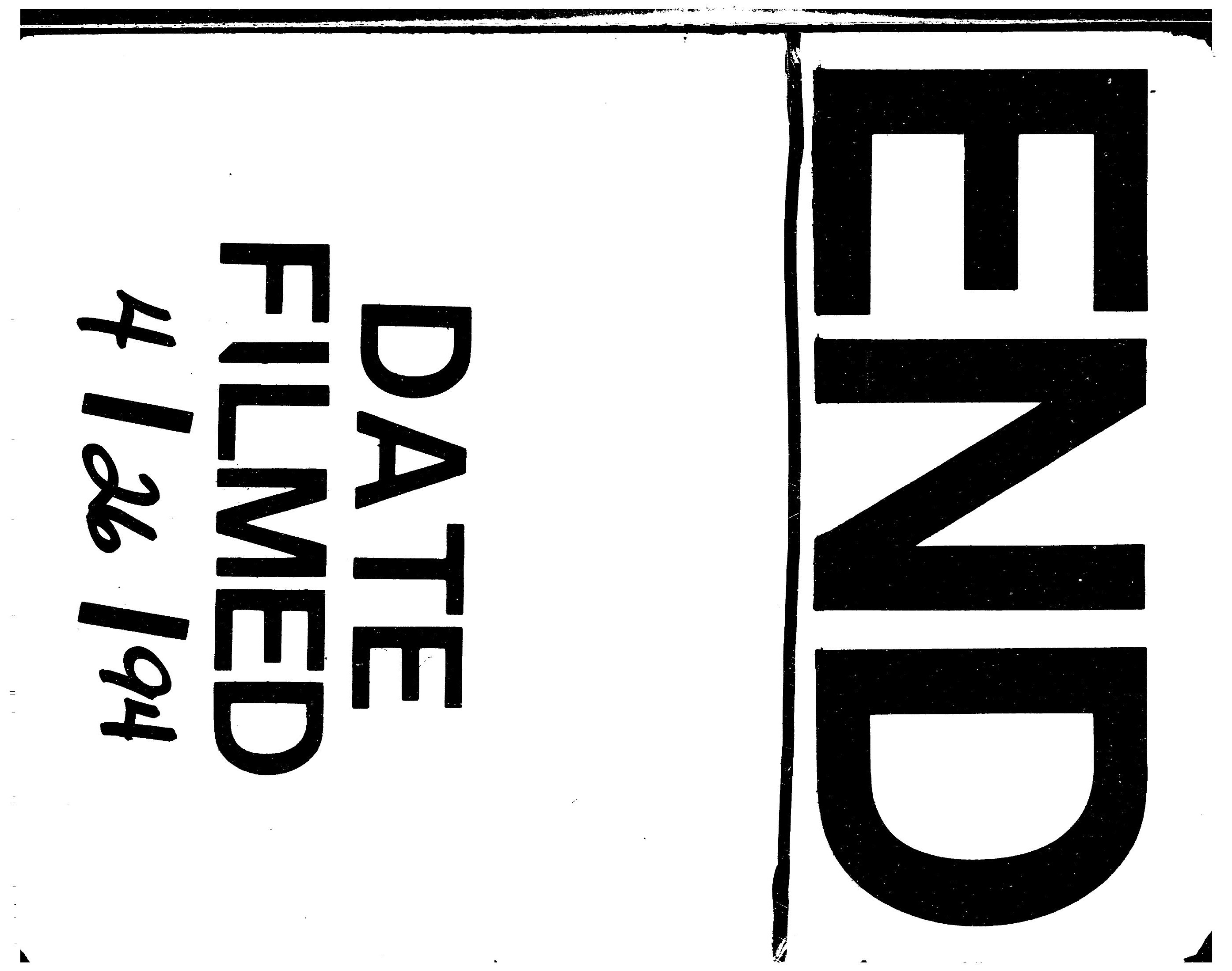


\#

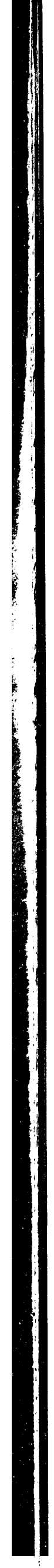

. .

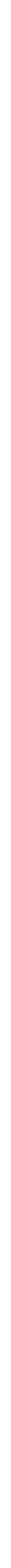

